\title{
Development of Level-of-Service Criteria based on a Single Measure for BRT in China
}

\author{
Yueying Huo \\ Inner Mongolia University \\ Jinhua Zhao \\ Massachusetts Institute of Technology \\ Jian Zhang and Feng Qiu \\ Southeast University
}

\begin{abstract}
Bus rapid transit (BRT) has gained popularity as a cost-effective way of expanding public transit services, and its level of service (LOS) is receiving increasing attention. However, relatively little is known about the precise criteria that can consistently and objectively classify the LOS of BRT into different levels. This paper introduces the measure of "unit delay" to develop BRT LOS criteria, defined as the sum of delays a bus experiences at stops and intersections and on a $100 \mathrm{~m}$ link. Based on field surveys conducted on BRT in Changzhou, China, we obtained a unit delay data set and established BRT LOS criteria using Fuzzy C-means Clustering. The LOS criteria can be applied for operational, design, and planning analyses for BRT systems. A method to examine the operational conditions in spatial and temporal dimensions and pinpoint the service bottlenecks of a BRT system is presented.
\end{abstract}

Key words: Level of service criteria, bus rapid transit, unit delay, Fuzzy C-means clustering

\section{Introduction}

Bus rapid transit (BRT) combines the efficiency and reliability of rail service with the operating flexibility and lower cost of conventional bus service. Many cities are turning to BRT as a way to cost-effectively expand public transit services to relieve traffic congestion, reduce fuel consumption and carbon emissions, and increase mobility options for the poor (Cervero and Kang 2011). BRT has been implemented throughout Latin America and North America, Europe, Asia, Australia, and, now increasingly, in Africa and India (Deng and Nelson 2011). In China, BRT has expanded faster than in any other regions over the last five years (Fjellstrom 2010). By the end of 2014, BRT was implemented in 19 cities in 
China, and its total length has reached $529 \mathrm{~km}$ (Institute for Transportation \& Development Policy 2015).

Level of service (LOS) as a way to quantify service quality of BRT is receiving increasing attention. BRT LOS criteria, which classify the LOS of BRT into several levels, are an effective method to evaluate the service quality of BRT and can provide useful tools for communicating the service quality of BRT to laypersons and decision makers. BRT LOS criteria also can be used for BRT design analysis to allow a new or modified BRT facility to operate at a desired LOS. Typically, analysts can use BRT LOS criteria to determine values for elements such as stop space, berth number, and route number at one stop.

Issues about the planning, design, and passenger-carrying capacity of BRT have been well researched in China (Xu 2007, Mo 2007, Wu 2010, Lu 2011). Researchers outside China focus more on the impacts of BRT on land use, fuel consumption, pollution emissions, and traveler behavior (Zargari and Khan 2002, McDonnell et al. 2008, Mishra et al. 2010, Perk et al. 2010, McDonnell and Zellner 2011, Aiga 2014). However, relatively little academic focus has centered on BRT LOS criteria. Therefore, this study generated scenarios to investigate BRT LOS criteria in China.

First, research progress on LOS criteria of urban streets and public transit are reviewed. This is followed by the introduction of BRT development in China. Next, a research methodology involving measure selection, level number of LOS, theoretical approach for LOS partitioning, and supporting data sources is presented. Finally, BRT LOS criteria are established and their applications are discussed.

\section{Literature Review}

The concept of LOS was introduced in the 1965 edition of the Highway Capacity Manual $(H C M)$, which presented the now-familiar letter-grade system for characterizing the quality of operations on a variety of traffic facilities, from intersections to freeways (Roess et al. 2010). LOS is a quantitative stratification of a performance measure or measures that represent quality of service (TRB 2010). HCM defines six levels of service, ranging from A to $F$, with LOS A representing the best operating conditions from the traveler's perspective and LOS $F$ the worst.

The 2010 edition of HCM provides LOS criteria for freeways, multi-lane highways, twoway highways, urban streets, and intersections. BRT is a portion of an urban street; thus, the LOS criteria for urban streets in HCM 2010 are introduced below. An urban street right-of-way is shared by four types of travel modes-automobile, pedestrian, bicycle, and transit-and each mode uses its assigned portion of the right-of-way. HCM 2010 provides separate LOS criteria for these four modes on urban streets. Through-vehicle travel speed and auto LOS scores are used to characterize automobile LOS. Pedestrian LOS scores and average pedestrian space on a sidewalk are used as measures to classify pedestrian LOS into six levels. LOS scores reported by travelers are used to describe LOS for bicycle and transit modes. The LOS score is the common service quality measure for the four modes on urban streets. Therefore, it can be used to compare the relative quality of service provided to the users of each mode and to estimate the impact of reallocating street rightof-way on each mode's quality of service. 
LOS criteria in HCM are more suitable for traffic conditions in North America, particularly the United States. Bhuyan and Rao (2010), Mohapatra et al. (2012), Das and Bhuyan (2014) addressed LOS criteria for highly heterogeneous traffic flow on urban streets in India using a clustering algorithm and found that speed thresholds for LOS criteria in India are lower than those mentioned in HCM. Historically, HCM has used a single performance measure as the basis for defining LOS. Different from this, researchers in China use multiple measures to characterize LOS for urban streets. For example, Xu et al. (2008) proposed LOS criteria for urban streets by considering density, speed, volume-to-capacity ratio, and service flow rate.

BRT is a new form of public transit; LOS criteria of public transit are discussed below. The Transit Capacity and Quality of Service Manual, 3rd Edition (TCQSM 2013), provides systematic and detailed introductions to LOS criteria for public transit (TRB 2013). For fixedroute transit service, TCQSM 2013 uses two categories of service measures-availability and comfort \& convenience-to evaluate service quality. The measures for availability include frequency, service span, and access. The measures for comfort \& convenience include passenger load, reliability (on-time performance and headway adherence), and transit-auto travel time ratio. TCQSM 2013 also presents LOS criteria (called quality of service tables) for each service measure, which eliminate the LOS letters associated with the transit quality of service measures. Eliminating the letters has allowed LOS criteria to show more or fewer service levels, as appropriate, rather than being forced to fit the levels to the six letters, as before. The selection of thresholds in LOS criteria for service measures represents a collective professional judgment.

Recognizing that transportation planners and engineers generally are comfortable with letter-grade LOS, TCQSM 2013 introduced the transit LOS score as the measure of transit quality on urban streets. This measure provides a single transit LOS letter as its output while incorporating most of the factors included in the manual's transit service quality framework. This measure also can be incorporated into an overall evaluation of the service quality provided to all urban street users - transit passengers, pedestrians, bicyclists, and motorists.

The LOS criteria of public transit are characterized by multiple measures in TCQSM 2013. The disadvantage of an LOS evaluation system with multiple measures is that it does not allow definite benchmarking of different systems (Xin et al. 2005). Different from the approach adopted in TCQSM 2013, Chen (1999) and Xu (2001) developed LOS criteria for exclusive bus lanes based solely on a single measure-delay.

\section{BRT in China}

BRT has expanded and evolved in China since the first median bus lanes were introduced in Kunming in 1999. However, with no special BRT buses or pre-board fare collection, and no significantly improved station environment, Kunming is not regarded as a full-fledged BRT system. Beijing was, in 2005, the first full BRT system to open in China, in the sense that it provides high-capacity BRT buses, fare collection at stations rather than on buses, and dedicated bus lanes for most of its length (Fjellstrom 2010). 
Information on running ways, stop space, fare collection, ridership, and speed of BRT systems in China is detailed in Table 1. A majority of BRT systems in China use median bus lanes as running ways and on-line stations rather than bus bays for bus stopping. Fare collection is mainly off-board, and passengers pay or swipe at stations. Because of low-floor buses or high platforms, most BRT systems allow level passenger boarding and alighting. $B R T$ ridership among these cities varies greatly, ranging from 600 passengers per hour per direction in Zhoushan to 27,400 passengers per hour per direction in Guangzhou. Peakhour speeds in city centers also differ, with $39 \mathrm{~km} / \mathrm{h}$ in Zaozhuang compared to about $10 \mathrm{~km} / \mathrm{h}$ in Urumqi.

TABLE 1. Design and Operation Features of BRT in China

\begin{tabular}{|c|c|c|c|c|c|c|c|}
\hline City Name & $\begin{array}{l}\text { Bus Lane } \\
\text { Length } \\
(\mathrm{km})\end{array}$ & Running Way & $\begin{array}{l}\text { Mean Stop } \\
\text { Space (m) }\end{array}$ & $\begin{array}{c}\text { Fare } \\
\text { Collection }\end{array}$ & $\begin{array}{l}\text { Boarding/ } \\
\text { Alighting }\end{array}$ & $\begin{array}{c}\text { Peak Ridership } \\
\text { (passengers/ h/ } \\
\text { direction) }\end{array}$ & $\begin{array}{c}\text { City Center } \\
\text { Peak Speed } \\
(\mathrm{km} / \mathrm{h})\end{array}$ \\
\hline Beijing & 59 & Median lane & 940 & Pre-board & No step & 2,750 & $18-20$ \\
\hline Changzhou & 51.9 & Median lane & 900 & Pre-board & No step & 2,650 & 19.5 \\
\hline Guangzhou & 22.5 & Median lane & 880 & Pre-board & Both & 27,400 & $17-19$ \\
\hline Hangzhou & 18.8 & Median and curbside lane & 1100 & Pre-board & No step & 6,300 & 18 \\
\hline Zhengzhou & 50.3 & Median lane & 750 & Pre-board & No step & 7,230 & 17 \\
\hline Dalian & 9 & Mainly median lane & 1350 & Pre-board & No step & 6,430 & 19.3 \\
\hline Jinan & 41.6 & Median lane & 760 & Pre-board & No step & 2,050 & 17.5 \\
\hline Hefei & 7.2 & Median lane & 850 & Pre-board & Step & 3,600 & $16-18$ \\
\hline Changde & 18.9 & Median lane & 820 & Pre-board & No step & 800 & 31 \\
\hline Lanzhou & 8.6 & Median lane & 650 & Pre-board & No step & 6,550 & 22 \\
\hline Lianyungang & 34 & Median lane & 1210 & Pre-board & No step & 1,650 & 18 \\
\hline Xiamen & 48.9 & Elevated road & 1300 & Pre-board & No step & 8,360 & 27 \\
\hline Yancheng & 16 & Median lane & 690 & Pre-board & No step & 1,300 & 18 \\
\hline Yinchuan & 17 & Median lane & 800 & Pre-board & Both & 3,600 & 15 \\
\hline Zaozhuang & 33 & Median lane & 1635 & Both & No step & 1,400 & 39 \\
\hline Urumqi & 28 & Mainly median lane & 880 & Pre-board & No step & 6,950 & $10-13$ \\
\hline Chengdou & 28.8 & Elevated road & 1020 & Pre-board & No step & 6,650 & 29 \\
\hline Zhongshan & 12.6 & Median lane & 1000 & Pre-board & Step & 820 & 22.7 \\
\hline Zhoushan & 23 & Curbside lane & 2700 & Pre-board & No step & 600 & 19 \\
\hline
\end{tabular}

All BRT systems in China use on-line stations.

Source: Bus Rapid Transit Information. www.worldbrt.net/defaulten.aspx, accessed April 8, 2015.

To collect data for this research, surveys were conducted on the Changzhou BRT, which opened in January 2008 and currently has two trunk routes, six branch routes, three section routes, and two loop routes. Its operation mode is direct-service operations. The running ways are dedicated median bus lanes that are about $3.75 \mathrm{~m}$ wide. The system has 58 stations, each about $3 \mathrm{~m}$ wide and $60 \mathrm{~m}$ long and spaced roughly $900 \mathrm{~m}$ apart and located close to intersections. The system has 60 BRT vehicles, most of which are $18 \mathrm{~m}$ articulated buses. Monitoring facilities are installed throughout system to prevent other vehicles 
from entering. This system also includes intelligent technologies such as automated vehicle location (AVL), real-time passenger information, and transit signal priority (TSP).

\section{Methodology}

\section{Measure Selection for LOS of BRT}

BRT is a new type of public transit. Since BRT is located on urban streets, it has the characteristics of both public transit and urban streets. In HCM, a single measure is used to define the LOS of urban streets; however, TCQSM adopts multiple measures to evaluate LOS of public transit. This paper considered both HCM and TCQSM when selecting service measures for the LOS of BRT; a single measure to evaluate the LOS of BRT was sought and was selected through identifying the most pressing problems of bus transit in China from multiple service aspects such as availability, reliability, etc.

Availability, economy, comfort \& convenience, and reliability are important aspects of bus transit service. At present, the Chinese government attaches great importance to public transit; many bus routes and stops are being planned for Chinese cities, and service times have been extended. Travelers can conveniently access bus service, availability in space and time are not a problem, and bus fares are low and affordable. Reliability is the most significant problem, and it is particularly urgent that it be improved. Late arrivals and departures and unreliable wait and travel times are major weaknesses. Comfort is also a significant problem, with buses too crowded during peak hours and no air conditioning in older buses. Lack of comfort is a derived problem and is exacerbated by unreliability; for example, uneven headways at stops, uncertain bus arrival times, and unreliable travel times all lead to passenger imbalance and crowding on buses. Comfort will be improved with improvements in reliability.

A BRT system includes links, stops, and intersections. Operational conditions on links are relatively unimpeded because of the use of exclusive rights-of-way, but stops and intersections can be traffic bottlenecks in a BRT system, where bus queues and bunching often occur, resulting in bus delays. Although delay of one bus at one stop or intersection may be small, the combined delay of all buses at all stops and intersections can be significant and can result in large economic losses. Accumulated delays at stops, intersections, and links result in unreliability of the entire BRT operation. Therefore, BRT delay-the sum of delays of buses at all stops, intersections, and links within a BRT system-is the appropriate measure of BRT LOS.

\section{Estimation Model for Delay}

This study aimed to develop BRT LOS criteria, but the LOS criteria based on BRT delay cannot provide a benchmark for comparing different BRT systems. Therefore, "unit delay" was used to develop BRT LOS criteria. Unit delay in this paper is defined as the sum of delays a bus experiences at stops and intersections and on a 100m link (Note: To compare the LOS of different BRT systems, "link" is a $100 \mathrm{~m}$ link; the delay on a $100 \mathrm{~m}$ link equals average delay per $100 \mathrm{~m}$ link).

A near-side stop is a bus stop immediately prior to an intersection at which buses stop to serve passengers before crossing the intersection. Operational conditions at near-side stops are the worst within the BRT network, as bus queueing and bunching become more 
severe under the additional interferences of traffic lights at downstream intersections. Bus delays at near-side stops are generated mainly from bus queueing and bunching, and bus delay at near-side stops includes delays at both stops and intersections.

Huo (2013) built a model for bus delay at near-side stops, as shown in Equation (1). This model was validated by data collected from near-side stops on the Changzhou BRT and bus transit in Vancouver, with accuracy of $81.32 \%$ and $75.07 \%$, respectively (Huo 2013, Huo 2015). This model was used to calculate the unit delay shown below.

$$
D=\left\{\begin{array}{l}
\frac{P_{0} \rho^{s} \rho_{s}}{\lambda s !\left(1-\rho_{s}\right)^{2}}+\frac{\theta\left[P_{(n>s)}\left(1-\frac{1}{s !}+\frac{t_{r}}{C}\right)+\sum_{n=2}^{s} \frac{P_{n}(n !-1)}{n !}+\frac{P_{(n>s)}(s !-1)}{s !}+\frac{\left(1-P_{0}\right) t_{r}}{C}\right]}{\lambda} \\
\quad \times \sqrt{\frac{P_{0} \rho^{s} \rho_{s}\left(1+\rho_{s}\right)}{s !\left(1-\rho_{s}\right)^{3}}-\left(\frac{P_{0} \rho^{s} \rho_{s}}{s !\left(1-\rho_{s}\right)^{2}}\right)^{2}}, s>1 \\
\frac{\rho / \mu}{1-\rho}+\frac{\theta\left(P_{(n>1)}+1-P_{0}\right) t_{r}}{C \lambda} \sqrt{\frac{\rho^{2}-2 \rho^{4}+\rho^{5}}{(1-\rho)^{3}}}, s=1
\end{array}\right.
$$

Where, $D$ represents the delay a bus experiences at near-side stop (s/vehicle), $\theta$ indicates the fraction of waiting time variation resulting from buses being blocked from exiting a stop by buses in front and/or by a red light (estimated to be 0.467 based on collected data from Changzhou BRT), $\lambda$ represents the mean arrival rate (vehicle/s), $\mu$ represents the mean service rate (vehicle/s/berth), $s$ represents the berth number at the stop, $t_{r}$ represents the red time at the downstream intersection $(s), C$ represents the cycle length at the downstream intersection $(s), n$ represents the number of buses included in service and in queue at the stop, $\rho=\lambda / \mu, \rho_{s}=\lambda /(s \mu), P_{0}=\left[\sum_{n=b}^{s-1} \frac{\rho^{n}}{n !}+\frac{\rho^{s}}{s !\left(1-\rho_{s}\right)}\right]^{-1}$ for $s>1$ and $p_{0}=1-\rho$ for $s=1$, and $P_{(n>s)}=1-\sum_{n=0}^{s} \frac{\rho^{n} P_{0}}{n !}$.

\section{Theoretical Method for LOS Criteria}

Defining LOS criteria is a classification problem, and from the literature it was determined that cluster analysis is the most suitable technique for solving this kind of problem (Bhuyan and Rao 2010, Mohapatra et al. 2012, Das and Bhuyan 2014). Fuzzy C-Means clustering (FCM), developed by Dunn in 1973 and improved by Bezdek in 1981, is a cluster analysis method derived from fuzzy logic (Bezdek et al. 1984) that allows a dataset to be grouped into $C$ clusters, with every data point in the dataset belonging to every cluster to a certain degree, which makes the cluster result of FCM closer to reality (Bezdek et al. 1984). Therefore, FCM is the most frequently-used cluster analysis method (Yue et al. 2014). In the study of LOS criteria, Bhuyan and Rao (2010) applied FCM to develop LOS criteria for urban streets in India. Mohapatra et al. (2012) used a hybrid algorithm based on FCM in association with a genetic algorithm (GA) to investigate LOS criteria for urban streets. Cheol and Stephen (2002) applied FCM and other methods to develop real-time induc- 
tive-signature-based LOS criteria for a signalized intersection surveillance system. Therefore, based on analysis of literature, this study used FCM to establish BRT LOS criteria.

\section{Level Number Defined}

In China, LOS for a roadway facility, such as a freeway or an urban street, is classified into four levels (Xu et al. 2008), which is different from HCM's six levels. BRT is a part of urban streets; thus, the LOS of BRT was defined as four levels in this study, ranging from 1 to 4 , with LOS 1 representing the best operating conditions and LOS 4 the worst.

As mentioned, unit delay was used to establish BRT LOS criteria; therefore, BRT LOS criteria were interpreted in the style of Table 2, where $D_{0}$ represents unit delay in BRT and $d_{1}, d_{2}$, and $d_{3}$ represent unit delay thresholds. Establishing BRT LOS criteria is determining unit delay thresholds for partitioning different levels, i.e., determining the values for $d_{1}$, $d_{2}$, and $d_{3}$ in Table 2 .

TABLE 2.

\begin{tabular}{|c|c|}
\hline LOS & Unit Delay \\
\hline 1 & $D_{0} \leq d_{1}$ \\
\hline 2 & $d_{1}<D_{0} \leq d_{2}$ \\
\hline 3 & $d_{2}<D_{0} \leq d_{3}$ \\
\hline 4 & $D_{0}>d_{3}$ \\
\hline
\end{tabular}

\section{Unit Delay Data Set Used for BRT LOS Criteria}

Unit delay refers to the sum of delays a bus experiences at stops or intersections and on $100 \mathrm{~m}$ links. Analyzed as above, bus delay at near-side stops includes delays at both stops and intersections. Thus, we used the estimation model for bus delay at near-side stops (Equation [1]) to obtain unit delay data set: 1) determine the variable values in Equation $(1), 2)$ match the values of the variables and form different variable value combinations, 3) calculate the sum of delays at stops and intersections under each variable value combination with Equation (1), and 4) obtain the unit delay data set by adding the delay on a $100 \mathrm{~m}$ link to the sum of delays at stops and intersections.

The variables in Equation (1) include mean arrival rate, mean service rate, and berth number at a near-side stop and red time and cycle length at downstream intersections. Mean arrival rate is the mean of the number of arrival buses per unit time. Mean service rate is the service capacity of each berth at a stop and is the reciprocal of average service time. Service time is the time that a bus spends at a stop and equals the difference between the time it exits the stop and the time it begins to decelerate.

To gain values for these variables and delay on a $100 \mathrm{~m}$ link, three types of field surveys were conducted for the Changzhou BRT on April 11 and 12, 2013:1) mean arrival rate and mean service rate at near-side stops, 2) berth number, red time, and cycle length, and 3) delay on links. For the first type of survey, the two busiest near-side stops were selected, with one surveyor for each stop, who recorded all buses arriving at the stop from 9:0018:00 and, for each arriving bus, recorded the time when it began to decelerate $t_{1}$ and the time when it exited the stop $t_{2}$. Values for mean arrival rate were derived by counting the 
number of arriving buses per hour. Service time for each bus is $t_{1}$ minus $t_{2}$, and average service time is the mean of service time of all arriving buses per hour. Values for mean service rate were derived by calculating the reciprocal of average service time.

For the second type of survey, 10 near-side stops were randomly selected, with one surveyor to record berth numbers, red times, and cycle lengths. For the third type of survey, 10 links near the selected stops were chosen, with one surveyor to observe bus delay. It is found that buses are almost unimpeded on BRT links due to exclusive rights-of-way, and bus delay on $100 \mathrm{~m}$ links is approximately $0.5 \mathrm{~s}$.

Based on the collected data from the field surveys, the variable values used to produce the unit delay data set were identified, as shown in Table 3. The variable ranges in Table 3 cover as many values as possible in practice and, thus, the unit delay data set is feasible for BRT LOS criteria.

TABLE 3.

Values for Variables in Equation (1)

\begin{tabular}{|l|c|c|c|}
\hline \multicolumn{1}{|c|}{ Variables } & Ranges & Step Size & Number \\
\hline Mean arrival rate (vehicle/h) & $20-80$ & 5 & 13 \\
\hline Mean service rate (vehicle/h/berth) & $60-120$ & 10 & 7 \\
\hline Berth number & $2-4$ & 1 & 3 \\
\hline Red time (s) & $60-130$ & 10 & 8 \\
\hline Cycle length (s) & $90-150$ & 10 & 7 \\
\hline
\end{tabular}

Based on the variable values in Table 3, all the values for all the variables were matched, and different variable value combinations were generated accordingly. The values for mean arrival rate, mean service rate, berth number, red time, and cycle length were 13,7 , 3,8 , and 7 , respectively. Therefore, the number of variable value combinations was 15,288 $(13 \times 7 \times 3 \times 8 \times 7)$.

The variable values in Equation (1) were set in the variable value combinations, and the sum of delays a bus experiences at stops and intersections under all the variable value combinations was calculated. Finally, $0.5 \mathrm{~s}$ (bus delay on a $100 \mathrm{~m}$ link) was added, and the unit delay data set was obtained, at 15,288.

\section{BRT LOS Criteria Results}

Based on the unit delay data set built above, BRT LOS criteria using FCM were established. Cluster numbers in FCM are the four level numbers of BRT LOS. Cluster centers in FCM are median values between adjacent levels of BRT LOS, and thresholds between adjacent levels can be determined on the basis of the median values. Cluster results for unit delay using FCM are shown in Table 4.

TABLE 4.

Cluster Results of Unit Delay Category $\quad$ Cluster Centers of Unit Delay (s) using FCM

\begin{tabular}{|c|c|}
\hline 1 & 7 \\
\hline 2 & 18 \\
\hline 3 & 37 \\
\hline 4 & 68 \\
\hline
\end{tabular}


By calculating the average values of adjacent cluster centers, the thresholds between adjacent levels of BRT LOS were determined, and BRT LOS criteria were established, as shown in Table 5. Unit delay was less than 13s at LOS 1; when unit delay increased to 28s, BRT LOS deteriorated to LOS 2; when unit delay was between $28 \mathrm{~s}$ and $53 \mathrm{~s}$, it was LOS 3; and when unit delay was more than $53 \mathrm{~s}$, it was the worst operating condition, LOS 4 . What the four LOS ranges represent from a transit operator perspective are shown in Table 5. (Note: The variables for the unit delay data set were collected from BRT systems in which bus overtaking maneuvers are prohibited; thus, the BRT LOS criteria in Table 5 are suitable only for BRT systems in which bus overtaking maneuvers are prohibited.)

TABLE 5.

BRT LOS Criteria in Changzhou

\begin{tabular}{|c|c|l|}
\hline LOS & Unit Delay (s) & \multicolumn{1}{c|}{ Operator Perspective } \\
\hline 1 & $<13$ & $\begin{array}{l}\text { Slight bus queueing and bunching at a stop and intersection; transit agency } \\
\text { does not need to take traffic control actions. }\end{array}$ \\
\hline 2 & $13-28$ & $\begin{array}{l}\text { Moderate bus queueing and bunching at a stop and intersection; transit agency } \\
\text { needs to arrange traffic police to disperse bus flow during peak hours }\end{array}$ \\
\hline 3 & $28-53$ & $\begin{array}{l}\text { Frequent bus queueing and bunching at a stop and intersection; transit agency } \\
\text { needs to take action such as adjusting signal timing or increasing berth to } \\
\text { transform current BRT }\end{array}$ \\
\hline 4 & $>53$ & $\begin{array}{l}\text { Serious bus queueing and bunching at a stop, an intersection, and on a link; } \\
\text { government needs to construct new BRT routes to meet passenger demands. }\end{array}$ \\
\hline
\end{tabular}

Note: Unit delay refers to the sum of delays a bus experiences continuously at stops and intersections and on a 100m-long link within a BRT system.

\section{Applications}

The BRT LOS criteria established above have potential applications for operational, design, and planning analyses for BRT systems.

- Operational analyses review operational conditions (levels of service) of subsegments within BRT systems and generally are oriented toward current conditions of BRT systems. They aim at identifying operational bottlenecks of BRT systems and providing information for decisions on whether there is a need for improvements to an existing station, link, or facility.

- Design analyses apply the BRT LOS criteria to determine the required physical features that will allow a new or modified BRT to operate at a desired LOS. They are usually targeted at mid- to long-term implementation of BRT systems. Typically, analysts can use BRT LOS criteria to determine such elements as spacing and location of stations, berth number, frequency of bus service, and route number.

- Planning analyses typically focus on future conditions and provide information for decisions on whether there is a need to construct a new BRT and evaluate a series of alternatives.

Further studies are required to develop the methods for all three types of applications. The following presents one method for operational analysis.

A BRT's operational conditions vary in spatial and temporal dimensions; operational conditions differ in different sub-segments and during different time periods. Thus, oper- 
ational analysis should reflect operating conditions by sub-segment and by time period. Based on this idea, the following method was used to carry out an operational analysis.

First, divide a BRT system into several segments; beginning at a terminal, the sections between two BRT stations are identified as segments, and the division of that segment ends at the next terminal. The division method is illustrated in Figure 1.

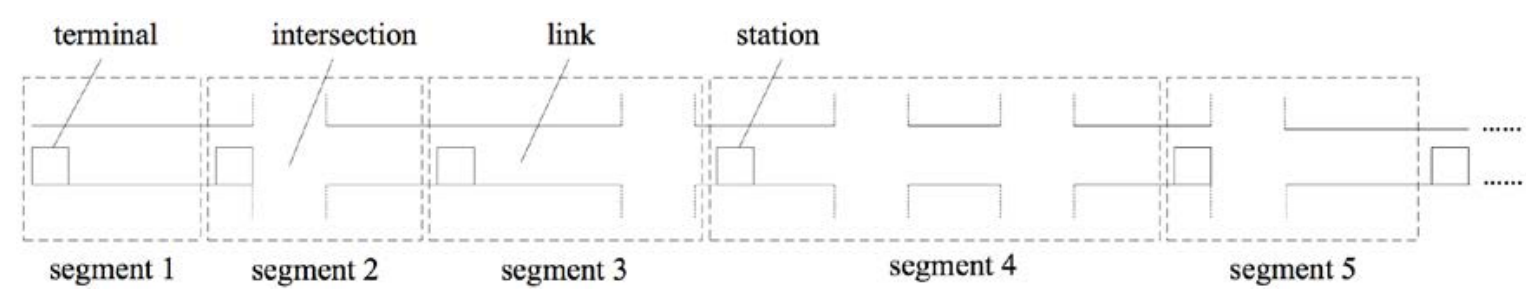

FIGURE 1. Method for dividing BRT into segments

Second, evaluate the operating conditions of each segment during all time periods, e.g., every $15 \mathrm{~min}, 20 \mathrm{~min}, 30 \mathrm{~min}$, etc. Table 6 shows the operational analysis for a segment. To complete the operational analysis for a segment, obtain data for the delays a bus experiences on links or at stations and/or intersections in the segment during all time periods; the types of delays can be obtained through field surveys or using existing models. Delays on links are converted into delays on a $100 \mathrm{~m}$ link; one or more intersections may be included within the segment (as indicated in the division method of segments). If there are no intersections, intersection delay is 0 . If there are two or more intersections, intersection delay equals the average delay of multiple intersections. Determine unit delay by adding these delays together. Then, based on the established BRT LOS criteria (Table 5), identify the levels of service for a segment during all time periods.

TABLE 6.

\begin{tabular}{|c|c|c|c|c|c|c|}
\hline \multicolumn{2}{|c|}{ Segment number } & \multicolumn{5}{|c|}{ Link length intersection included: Yes or No } \\
\hline $\begin{array}{l}\text { Time } \\
\text { Periods }\end{array}$ & $\begin{array}{l}\text { Delay on } \\
\text { Links (s) }\end{array}$ & $\begin{array}{c}\text { Delay on } \\
100 \mathrm{~m} \text { Link (s) }\end{array}$ & $\begin{array}{c}\text { Delay at } \\
\text { Station (s) }\end{array}$ & $\begin{array}{c}\text { Delay at } \\
\text { Intersection (s) }\end{array}$ & $\begin{array}{l}\text { Unit Delay for } \\
\text { Segment (s) }\end{array}$ & $\begin{array}{l}\text { LOS for } \\
\text { Segment }\end{array}$ \\
\hline $6: 00-6: 30$ & & & & & & \\
\hline $6: 30-7: 00$ & & & & & & \\
\hline 7:00-7:30 & & & & & & \\
\hline $7: 30-8: 00$ & & & & & & \\
\hline ....... & & & & & & \\
\hline $18: 30-19: 00$ & & & & & & \\
\hline 19:00-19:30 & & & & & & \\
\hline 19:30-20:00 & & & & & & \\
\hline
\end{tabular}

Finally, complete the operational analysis by obtaining the operational analysis results of all the segments. Table 7 shows the operational analysis table for a BRT, which is formed by gathering levels of service and unit delays of all segments during all time periods. The operational conditions by segment and by time period are clear, and the service bottlenecks of the BRT system are obtained. 
TABLE 7.

Operational Analysis Table for a BRT System

\begin{tabular}{|l|c|c|c|c|c|c|l|}
\hline \multicolumn{7}{|c|}{ LOS / Unit Delay (s) } \\
\hline Time Period & $\mathbf{1}$ & $\mathbf{2}$ & $\mathbf{3}$ & $\mathbf{4}$ & $\mathbf{5}$ & $\mathbf{6}$ & $\mathbf{\ldots . .}$ \\
\hline 6:00-6:30 & & & & & & & \\
\hline 6:30-7:00 & & & & & & & \\
\hline 7:00-7:30 & & & & & & & \\
\hline 7:30-8:00 & & & & & & & \\
\hline$\ldots \ldots .$. & & & & & & & \\
\hline 19:00-19:30 & & & & & & & \\
\hline 19:30-20:00 & & & & & & & \\
\hline
\end{tabular}

\section{Conclusions}

This study aimed to establish consistent and objective criteria for BRT LOS in China. To make operational conditions comparable across different BRT systems, a new measure of "unit delay" - the sum of delays a bus experiences at stops and intersections and on a $100 \mathrm{~m}$ link-was proposed to establish BRT LOS criteria. A unit delay data set was obtained by conducting field surveys and based on BRT LOS criteria in Changzhou established using FCM. These BRT LOS criteria can be applied to conduct operational, design, and planning analyses for BRT systems. They also provide a useful tool for communicating operational conditions of BRT to laypersons and non-technical policy makers. Finally, a method for operational analysis that applies BRT LOS criteria to examine operational conditions in spatial and temporal dimensions was presented.

One limitation of this study is that the LOS level number has been pre-determined to be 4, following a tradition of transportation facility LOS classification in China. However, the FCM method has the potential to decide the optimal number of levels on the basis of empirical data analysis. In addition, the BRT LOS criteria are based on objective delays. How to expand to and incorporate passenger perception into consideration remains an open question.

\section{Acknowledgments}

This research is jointly funded by the National Nature Science Foundation of China (No. 51208099, 51108080, and 51308115).

\section{References}

Aiga, S. 2014. "Does Bus Rapid Transit Influence Urban Land Development and Property Values: A Review of the Literature." Transport Reviews: A Transnational Transdisciplinary Journal, 34 (3): 276-296.

Bezdek, J. C., R. Ehrlich, and W. Full. 1984. “FCM: The Fuzzy C-Means Clustering Algorithm." Computers \& Geosciences, 10 (2-3): 191-203. 
Bhuyan, P. K., and K. V. K. Rao. 2010. "FCM Clustering Using GPS Data for Defining Level of Service Criteria of Urban Streets in Indian Context." Transport Problems, 5 (4): 105-113.

Cervero, R., and C. D. Kang. 2011. "Bus rapid Transit Impacts on Land Uses and Land Values in Seoul, Korea." Transport Policy, 18: 102-116.

Chen, L. 1999. "Research on Level of Service and Service Volume of Bus Reserved Lanes." Master's thesis, Institute of Civil Engineering, National Taiwan University.

Cheol, O., and G. R. Stephen. 2002. "Real-Time Inductive-Signature-Based Level of Service for Signalized Intersections." Transportation Research Record, 1802: 97-104.

Das, A. K, and P. K. Bhuyan. 2014. "Level of Service Criteria of Urban Streets Using Clustering Large Application (CLARA)." Advances in Transportation Studies an International Journal, B32: 75-88.

Deng, T. T., and J. D. Nelson. 2011. "Recent Developments in Bus Rapid Transit: A Review of the Literature." Transport Reviews, 31 (1): 69-96.

Fjellstrom, K. 2010. "Bus Rapid Transit in China." Built Environment, 36 (3): 363-374.

Huo, Y. 2013. "Evaluation Method on Level of Service of Exclusive Bus Lane." Doctoral dissertation, School of Transportation, Southeast University, Nanjing.

Huo, Y., W. Li, J. Zhao, and S. Zhu. 2015. “Modelling Bus Delay at Bus Stops.” Transport, 30(2).

Institute for Transportation \& Development Policy. Bus Rapid Transit Information. www. worldbrt.net/defaulten.aspx. Accessed April 8, 2015.

Lu, H. 2011. "Study on the Planning and Design Method of Bus Rapid Transit System." Master's thesis, School of Transportation, Shandong University, Jinan.

McDonnell, S., and M. Zellner. 2011. "Exploring the Effectiveness of Bus Rapid Transit: A Prototype Agent-Based Model of Commuting Behavior." Transport Policy, 18: 825835.

McDonnell, S., S. Ferreira, and F. Convery. 2008. "Using Bus Rapid Transit to Mitigate Emissions of $\mathrm{CO}_{2}$ from Transport." Transport Reviews, 28 (6): 735-756.

Mishra, R. K., M. Parida, and S. Rangnekar. 2010. "Evaluation and Analysis of Traffic Noise along Bus Rapid Transit System Corridor." Int. J. Environ. Sci. Tech., 6 (4): 37-750.

Mo, Y. 2007. "Study on Optimization Algorithm of Route Design of BRT." Traffic \& Transportation, 1.

Mohapatra, S. S., P. K. Bhuyan, and K. V. K. Rao. 2012. "Genetic Algorithm Fuzzy Clustering using GPS Data for Defining Level Oof Service Criteria of Urban Streets." European Transport, 52 (7).

Perk, V., M. Mugharbel, and M. Catalá. 2010. "Impacts of Bus Rapid Transit Stations on Surrounding Single-Family Home Values: Study of East Busway in Pittsburgh, Pennsylvania." Transportation Research Record, 2144: 72-79. 
Roess, R. P., M. A. Vandehey, and W. Kittelson. 2010. "Level of Service 2010 and Beyond." Transportation Research Record, 2173: 20-27.

Transportation Research Board of the National Academies. 2010. Highway Capacity Manual. Transportation Research Board, Washington, DC.

Transportation Research Board of the National Academies. 2013. TCRP Report 165: Transit Capacity and Quality of Service Manual, Third Edition. Transportation Research Board, Washington, DC.

Wu, Y. 2010. "Research on Bus Rapid Transit Planning." Master's thesis, School of Transportation, Chang'an University, Xian.

Xin, Y., L. Fu, and F. F. Saccomanno. 2005. "Assessing Transit Level of Service along Travel Corridors, Case Study using the Transit Capacity and Quality of Service Manual." Transportation Research Record, 1927: 259-267.

Xu, B. 2007. "Design of Urban Road Transit (BRT) System." Urban Roads Bridges \& Flood Control, 5: 36-40.

Xu, L., X. Yang, S. Ai, and B. Jin. 2008. "Study the Service Level of the City Roads in Beijing." Traffic and Transportation: 43-45.

Xu, P. 2001. "Research on Evaluation Method of Level of Service of Bus Reserved Lanes." Master's thesis, Institute of Civil Engineering, National Taiwan University.

Yue, S., T. Huang, and P. Wang. 2014. "Matrix Eigenvalue Analysis-Based Clustering Validity Index." Journal of Tianjin University (Science and Technology), 47 (8): 689-696.

Zargari, S. A., and A. M. Khan. 2002. "Fuel Consumption Model for Bus Rapid Transit." Journal of Advanced Transportation, 37 (2): 139-157.

\section{About the Authors}

YUeYiNG Huo (huoyueying2008@163.com) is an Assistant Professor at the Transportation Institute of Inner Mongolia University. She received a Ph.D. from the School of Transportation at Southeast University and studied at the University of British Columbia in 2011-2012. Her research interests include public transit planning, capacity, and service quality of public transit.

JinhUA ZhAO (jinhua@mit.edu) is an Assistant Professor in the Department of Urban Studies and Planning at Massachusetts Institute of Technology (MIT). He holds a Ph.D. in City and Regional Planning and a master's degree in Transportation and City Planning from the MIT. His research interests include urban development and planning in China, urban transportation systems in China, transportation economics, public transportation management, and urban information systems.

JIAN ZHANG (jianzhang@seu.edu.cn) is an Assistant Professor in the School of Transportation in Southeast University and deputy director of the Research Center for Internet of Mobility at Southeast University. He received a Ph.D. in Transportation Engineering from Southeast University and studied at the University of Wisconsin Madison in 2009-2010. 
His research interests include public transit planning, scheduling and intelligent transportation systems.

Feng QIU (afyouxiang@hotmail.com) is currently a Ph.D. Candidate in the School of Transportation at Southeast University. He earned a bachelor's degree from the Department of Geomatics Engineering at Southeast University and studied at the University of Maryland, College Park, in 2012-2013. His research interests include public transit services and innovative transport systems. 